\title{
Economic Support as the Foundation of the Social Welfare Strategy and Its Benefiting Obstacles
}

\author{
Dr. Blerina Xhakolli Reci \\ Department of Psychology, Education Faculty, "Aleksander Moisiu" University \\ blerina.xhakolligmail.com
}

\section{Doi:10.5901/mjss.2016.v7n2s1p61}

\section{Abstract}

\begin{abstract}
The purpose of this study is reviewing the economic support benefiting scheme to evaluate the level of the basic needs met; to discover the benefiting potential obstacles hindering the families in need to have access in this scheme; exploring and considering the beneficiaries opinion related to the changes of this policy in order to create a clear picture of its effect in easing the poverty level and diminish the social isolation as well as to offer relevant recommendations to the policy-makers and other groups of interest. Durres is a very interesting place where to study the effects of the economic support in our country because of the above mentioned specifics. The study is of transversal (cross-sectional) kind. The type of the study is quantitative. It integrates in one quantity view the quantitative and the qualitative aspects. The target population of the study are all the families include in the economic assistance scheme in Durres Municipality. The conclusions of this study on the obstacles to benefit from the economic support scheme are important assets to improve the existing scheme and the new one which is being pilot tested in Durres and other main cities. A new input of this study is the application online to benefit from the economic support scheme which will facilitate the application process which actually is operating very well but there still some issues to be resolved such as the calculation and the selection of individuals and families in need.
\end{abstract}

Keywords: economic support, obstacles, families in need, social security, social welfare.

\section{Economic Support, the Foundation of the Welfare and Social Security Strategy: Benefiting Obstacles}

\subsection{Welfare and social policies}

Welfare is a difficult concept to define. Welfare refers to collective assurance of financial support and services in order to improve the life quality of all the members of the society, and policies often called "social policies" or "social insurances" or "social security" (term often used in European context). Nowadays social security means offering financial support or other services based on the main principle of social services to protect individuals from any risks threatening their welfare or that of the whole society. There are different approaches toward the concept of social security. According to Marx perspective social security is used to legitimate capitalist social relations, whereas according to the feminist movement the main goal of this systems is to humble women and to consider them as persons to are obliged to serve the others. Therefore, today the term "to receive social services or support" has a negative connotation.

In general, individuals have access to social security services through predefined regulations giving them the right to receive certain benefits offered by social security systems applicable in a certain country. Since these systems are based on different principles and have gone through different ways of development even the funding mechanisms, the services they offer and the coverage of these services differ from country to country.

In many European countries, social security policies have change through the years and have become more important to the context of the major changes of the family structure, the weakening of the classic family pattern where the man provides for the family and the woman takes care of the children, the fertility decrease, population ageing etc. Based on the ability to keep the living standard, social stratification and state interaction, market and family in offering social security we can distinguish three kinds of social security systems: liberal, conservative and social-democratic. The feminist movement disagreed with this classification arguing that it does not take in consideration gender issues and the role of the family in offering social security, therefore scholars presented other classifications by distinguishing between family systems and non-family systems of social security/welfare. The non-family systems are considered to be the systems responsible for offering social security such as state social security system or the market system.

Since the 90-s social security policies are closely connected with family policies including the care for elderly people and other adults. Social security is a universal phenomena but its organization and the cooperation between the 
other actors involved responsible to provide it has always been an issues in many European countries. The traditional policies of social security have often been of one dimension, focusing mainly on only some services leaving aside many others. Because of the major changes of the family structure and Europe population, employment and social security models its flexibility has became a real issue for today's European policies.

Social security has many dimensions but we will focus mainly on the definition given by SOCCARE project funded by European Commission, which examined the organization of social security in many parts of Europe concentrating on four basic family patterns: 1) single parent families, 2) two parents families, 3) immigrant families and 4) families with small children and elderly adults members at the same time. According to SOCCARE project definition social security is "assuring the necessary assistance and supervision in supporting the children and the adults on every days activities". Social security maybe provided in the form of paid or un-paid labor (voluntary work) offered by professionals or non in the private or public sector.

\section{Social Security Policies And Poverty}

One of the main purposes of the social security/support policies is the reduction of the poverty. Are these policies really efficient? This subject has became part of the scientific circles debate as many scholars think that social policies easy the poverty whereas others are skeptic based on the fact that only a small part of these policies funds are benefited by the people who really need them, or the other fact they use is that providing social security services hinders the poor people initiative creating a "poverty trap", or high taxes and economic support reduces the economic increase overcoming the reduction of the poverty.

Many scholar support the argument that social security policies reduce poverty. Some other arguments suggests that policies which reallocate the incomes do not reduce the poverty, actually they contribute in increasing it. Three are the reasons for giving this argument. First, usually it is difficult to reallocate the funds and give them to the ones who really need, the poor. Actually is more probable that the ones benefiting come more from middle and upper class than from the low class. This is true for the USA and other industrialized countries where the social security systems are universal, which means they do not concentrate mainly on poor people. But beside these obstacles and difficulties the part of the funds reaching poor people should have a certain effect in reducing the poverty level.

The second reason has to do with the fact that the income reallocation encourages the dependency from this benefiting and as a result increases the poverty instead of reducing it. The beneficiaries get used to living with government money and are not encouraged to find a job. But these funds are not enough to meet all the needs they have or to bring them above the poverty level where they are living, therefore they fall on the poverty trap because of this social policy.

The third reason sustains the idea that social support policies have a negative effect on the economic level increase because the progressive taxation and other high benefits provided by the government reduce the investments and employment, failing in reducing the poverty.

On the other hand, there are arguments that social policies may have positive effects. Extensive programs of social policies can improve the employment flexibility by facilitating the retirement procedures or by creating new job vacancies and support women employment thus superseding the negative effect mentioned above.

\subsection{Policies of Social Security in Albania}

Often Albania is considered as a "difficult case" of regime change in comparison with other ex-communist countries of Central and East Europe. The long, difficult and sometimes chaotic road toward democratic and market system has placed the country in a disadvantaged position in comparison with the other countries because of the limited progress on these aspects. Historic disadvantage, such as the short experience as independent and democratic country, slow economic development, political division and totalitarian leadership explain the lingering transition, the problems and difficulties Albania is facing today. It is understandable that main reasons for the characteristic of today's Albanian society are to be found in the totalitarian communist regime ruling the country for more than 45 years, preventing the creation of the new leadership or of organizations with the appropriate vision to lead the country towards democracy after the communist fall.

The conflicts between the ex-communists and the anti-communist movement created political chaos bring the country closer to collapse many times. After the democracy establishment, the general reforms begin to be implemented under the political and economic term of "shock therapy", accompanied with high optimism. Nevertheless, in the middle of 90 's the reforms pace decreased because the democratic government begun to show signs of still existing relations with 
the ex-communist regime, by giving the power on the hands of one person. Bad management led to the crisis of pyramid schemes in 1997, and country was close to civil war. In 1997 new political general elections were organized and the new government continued with the implementation of different reforms. Anyways, these attempts did not gave positive results for the government and the country was characterized by deep political divisions, protagonist style of leadership, corruption and weak institutions. Now Albania is closer to the European integration meaning that certain standards should be met and certain challenges should be faced. Nevertheless, the problems above mentioned still dominate the social, political and the economic life in Albania.

In this frame, it would be of great interest to study the scheme of social security applicable in Albania, focusing on one of its regions such as Durres, as one of the districts with the biggest demographic, social and economic changes in the country. Durrës is one of the main prefectures in Albania, which has gone through major changes during the last 25 years as a result of immigration, migration which have contributed in the modification of the society and family related problems in this district, beside the economic problems which burden every family.

According to UNICF, Durres District is one of the most effected from the demographic movements during the 90's especially with the "exodus", during the riots in 1997and in the following years. According to Open Data Albania, Durres and Tirana are the only districts where during 2001-2013 the population increased with $8 \%$ and $26 \%$ respectively, whereas in the whole country it decreased with $8,2 \%$. Durres has the highest level of urbanization (78\%) in 2013, superseding Tirana pace of urbanization, while the pace of the population increase was approximately $50 \%$ during 2001 2013. Families coming from rural areas are mainly located in the suburbs. The many demographic changes of Durres city have created many social problematic which differ from one area to another, from one family to another based on the social levels and class characterizing the Albanian family. The 2011Census displays data on Prefecture level. According to this Census, Durres District is the forth biggest district based on the number of population afte Tirana, Fiers, Elbasan. Based on the same census in Albania approximately 6,7\%,5,7\% and 2,9\% of men and women above 15 years and the population above 65 years respectively have at least one handicap and Durres Disctrict figures are similar to the average figures of the country. In 2011 in Durres there were 1767 divorces people or 8,7\% of all the divorced people in Albania. There is only one residential center for children with handicaps offering services for only $3 \%$ of 1215 children who really need these services in the city.

According to INSTAT, Durres is one of the districts with the highest rate of poverty in the country. In 2008 approximately $16,2 \%$ of the population is poor in comparison with the country's average percentage of $14,3 \%$. Again based on INSTAT the poverty limit published in 2008 was 4891 lek per capita monthly. Considering this figure and the requirements of Economic support defined in the CMD no. 787, it is made very clear that the economic support covers only $36 \%$ of the needs of poverty limits for a family of 4 people.

In this context, Durres is an interesting study case in the effects of economic support in out country because of the above mentioned specifics. For this reason the main purpose of our study is the economic support scheme and its possibility to meet the basic needs of its beneficiaries, discovering the potential access obstacles to these services, reviewing the opinion of the people in need concerning different aspects of this policy in order to have a real estimation of the effect of social security scheme to ease poverty and social discrimination and to give the right recommendations to the policy-makers and other groups of interest.

\section{The Study Type and the Research Method Used}

The study is of transversal (cross-sectional) kind. The type of the study is quantitative. It integrates in one quantity view the quantitative and the qualitative aspects. The quantitave aspects of the study are made evident by the deep statistic analysis, by providing absolute figures and relative percentage, as well as the values of statistic significance. The qualitative part deals with collection of the opinions of the beneficiaries concerning aspects such as the social and family environment, the participation in the political life and the trust on some categories of state offices and officials.

Target population: the target population were all the families included in the economic support scheme of Durres Municipality during the year 2014.

Durres Municipality is divided in 5 administrative units. Each one of them has an Economic Support Office (ESO). Based on Durres Municipality data the number of families benefiting from the economic support scheme is approximately 400 yearly. This number changes every month because some new families begin to benefit from this scheme and some others stop benefiting from it. For example, in February 2014, there were in total 399 families included in the economic support scheme whereas in March 2014 there were 411 families with 1199 members in total included in the economic support scheme.

The criteria to be included in the study were: benefiting from the economic support scheme in Durres Municipality, 
in each of the ESO-s of this Municipality, independently from the gender or the duration of benefiting from this service; the person included in the study was more than 18 years. So every member of the benefiting families of this age and above coming to the relative ESO during June 2014, was a potential candidate to be part of our study. The economic support is received once a month, so every month all the beneficiaries have this right to come to the ESO and declare any changes in the family structure or in the employment status from "unemployed" to "employed". Whereas once every three months, the economic support beneficiaries should renew their document file in their relative ESO of the Administrative Unit, and prove that they are still unemployed ("the unemployed file")During this period economic support beneficiaries fill in a form declaring their actual economic situation. In a second moment this document is used by the Administrators of the ESO in relevant Administrative Units to make at post controls to verify the real situation of the family benefiting from the ES. For this reason the selection of June as the most appropriate month to collect the data was purposeful as the presence of the beneficiaries/head of the families at the ESO would be the highest. Of course selecting another three months period would not influence the collected data, for the above mentioned reason.

Sampling and its measuring: Based on Durres Municipality Data concerning the number of the individuals benefiting from the economic support scheme on March 2014, we calculated the most appropriate extent of the sample to define the special statistic relation between variables. In order to measure the extent of sample we used the program WINPEPI (188) by using series of social economic hypothesis such as the level of education, the level of obstacles to benefit from the economic scheme (how easy are the benefiting procedures). So we supposed that the percentage of the persons that thought that the benefiting procedures were complicated (one of the main obstacles) was $50 \%$, this level maximizes the sample extent. The level of statistic significance (alpha mistake or the value of P) was defined to be $5 \%$ (two-ways) and the study power was 80\%. Based on these suppositions and on conservative extent we calculated the minimal extent of the sample should be 260 persons (52 persons for each administrative unit). Since we were going to interview only one person per family, with this sampling we would be able to represent more than $50 \%$ of the families benefiting from the economic support in Durres Municipality.

The list of the individuals benefiting from the economic support in Durres was not available for us. Therefore at every ESO of every administrative unit we interviewed 52 persons chosen randomly. If any one of them would not agree to be interviewed we would pass on the next person coming to the ESO to receive the economic support. In order to avoid interviewing two persons from the same family we ask them previously if that had any information for this kind of interview.

At the end we interviewed in total 260 persons. After reviewing all the interview forms we noticed that 28 of them had deficiencies in filling in the basic variables of this study. For this reason these interviews were removed from the database thus leaving us with 232 persons interviewed to make more elaborate analysis. At the end the final level of participation in the study was $89.2 \%(232 / 260)$.

\subsection{Data collection}

Data collection was made possible by personally interview the individuals participatin in the study by an data collection trained interviewer.

In total 5 interviewers were trained (one interviewer for each EOS in the administrative units of Durres Municipality).

A compiled interview (half-structured) with open and closed questions was used to collect the data, which explored different aspects of the economic support.

Before widely using the questionnaire, it was tested on a small number of individuals (20 individuals/head of families benefiting from the ES) who were benefiting since April 2014 in order to practically calculate the efficiency and the confidence of the questionnaire. Considering the pre-test results we made some changes in the questionnaire such as leaving the age and education as numeric open variable; to investigate the individuals interviewed perception of different state officials sincerity and the confidence on them we decided to use the Likert scale of 5 categories instead of the scale with 3 categories; we increased the number of dimensions addresses by the questionnaire such as the section dealing with the social networks and friends support in case of need. In relation to the 12 question exploring the obstacles to benefit from the economic support scheme, we calculated the inner stability coefficient through Cronbach's alpha test.

This statistic of 0.770 level representing an inner stability well-moderated.

\subsubsection{Review of the data related to the economic support}

The subject of this study were benefiting from the economic support approximately for 7-8 years, especially women were 
benefiting for a relatively longer period than males ( 8,8 years vs 6,7 years, respectively $P=0.006$ ). The average age of the beneficiaries would increase in parallel with the benefiting period.

The main reason to apply for benefiting from the economic support was unemployment declared by the $66.8 \%$ of the interviewees, followed by difficult economic situation (15.1\%), handicap (7.8\%) and divorce (3.9\%). There more females than males declaring that divorce was the reason they wanted to benefit from the economic support (6.6\% vs $0.9 \%$ respectively). This difference had a statistic significance at the limit $(P=0.052)$. On the other side, two third of the interviewee (64.7\%) were looking for a job while they receiving the economic support $(57.4 \%$ of females and $72.7 \%$ of males, $\mathrm{P}=0.015)$

\subsection{Summary of the data related to the obstacles to benefit from the social support}

Concerning the obstacles in benefiting from the economic support, $37 \%$ of the interviewees thought that procedures were not simple, 25\% and 30\% thought that they are not transparent and the required documentation is not appropriate, 32\% think that there are people abusing with the procedures, 55\% think that there are people who benefit wrongfully from the economic support, $5 \%$ and $11 \%$ think that you have to bribe someone or have strong support from someone inside to benefit from the economic support ,43\% think that the time limits are not respected, $12 \%$ think that the political orientation effects the benefit from the ES, $20 \%$ and $33 \%$ think that the employees of the ESO do not explain at all or are not willing to give information on the benefiting procedures and requirements of $E S$, and $51 \%$ think that the information in the media related to ES is not enough or clear. This last figure is of a great interest because it shows that the main information resource for the interviewees is TV. In general, we do not noticed statistic significant differences between females and males interviewed concerning the benefiting obstacles accept the non transparent procedures $(30.3 \%$ of females and $18.2 \%$ of males, $\mathrm{P}=0.032)$ and the need to know someone "important" to benefit from the ES scheme $(14.8 \%$ of the females and $6.4 \%$ of males, $P=0.040$ ).

Concerning the average number of the obstacles of benefiting the economic support it was $3.5 \pm 3.5$ obstacles. In $16.4 \%$ of the cases the interviewees did report none of the listed obstacles, in $16.8 \%$ of the cases reported one obstacle, in $15.5 \%$ of the cases reported two obstacles, in $11.6 \%$ of the cases reported three obstacles, in $9.9 \%$ of the cases reported 4 obstacles. Nevertheless, more than half of the interviewees (51.3\%) reported at least three obstacles whereas $30.3 \%$ of them reported $5-12$ obstacles to benefit from the economic support, thus presenting a very concerning figure.

Females reported an average higher number of obstacles in comparison with the males (3.81 vs. 3.15, respectively) but the difference it not significant $(P=0.113) A$ clear negative connection was noticed between the average number of obstacles and level of education: between persons with 0-4, 5-8 and $>8$ years of education the average number of obstacles was $6.44,2.78$ and 2.51 , respectively $(P<0.001)$. Statistically significant relation was noticed even with the health situation, the average number of obstacles would increase every time the health situation would worsen. Concerning the vulnerable persons and their families the tendency was the older their age and the bigger their number the more the obstacles they had to overcome, even though these number did not reach the statistical significance.

The relation between the obstacles to benefit from the economic support and the education was moderate (the correlation coefficient Speraman's rho $=-0.319$ ). another moderate relation was notice with happiness level in general, wherever the happiness would decrease the obstacles number would increase (the correlation coefficient Speraman's rho $=0.262$ ) whereas the relation between the age, the number of the persons vulnerable and the duration of the benefiting time was weak and not significant.

The questionnaire exploring the obstacles for benefiting from the economic support scheme showed a strong inner stability (Cronbach's alpfa $=0.847$ ) and the correlation coefficient split-half $=0.666$, thus evidencing a high confidence in the instrument.

In relation to the main obstacles effecting the benefiting from the economic scheme, the factorial analysis data showed that there are four main obstacles, such as:

1. Procedures simplicity;

2. Procedures transparence;

3. The documents to be submitted; and,

4. Providing clear information by the media and the responsible institutions on the benefiting requirements.

Based on the factorial analysis, these components are responsible for approximately $66 \%$ of the variety concerning the benefiting obstacles. 


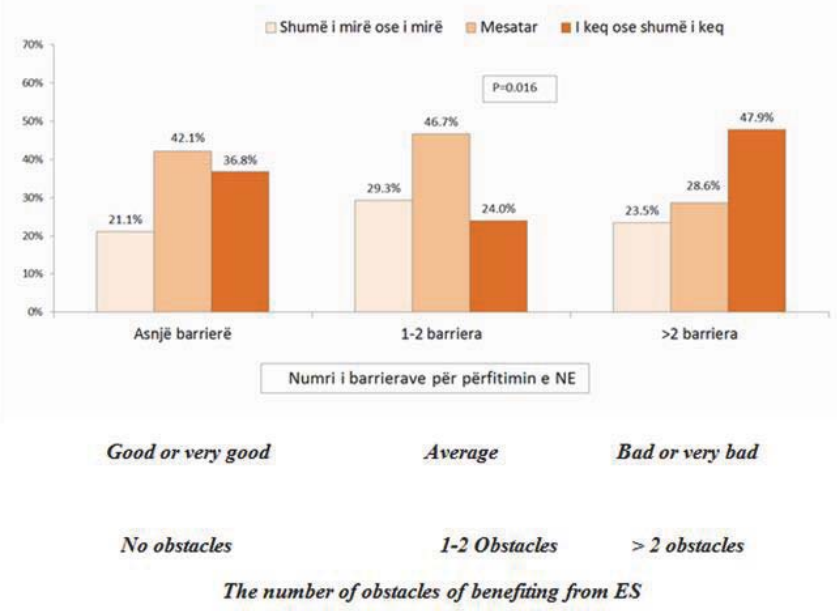

\subsection{Obstacles of benefiting from economic support (ES)}

The following tables display the distribution of the study subjects according to the obstacles of benefiting from the economic support.

The following table: Obstacles of benefiting from economic support based on the gender

\begin{tabular}{|c|c|c|c|c|}
\hline \multirow{2}{*}{ Obstacles of benefiting from economic support (1-6) } & \multirow{2}{*}{ Total } & \multicolumn{2}{|c|}{ Gender } & \multirow{2}{*}{$P$ value } \\
\hline & & Males $(n=110)$ & Females $(n=122)$ & \\
\hline $\begin{array}{l}\text { Simple Procedures } \\
\text { NO } \\
\text { Yes }\end{array}$ & $\begin{array}{l}86(37.1)^{*} \\
146(62.9)\end{array}$ & $\begin{array}{l}35(31.8) \\
75(68.2)\end{array}$ & $\begin{array}{l}51(41.8) \\
71(58.2)\end{array}$ & $0.116{ }^{\dagger}$ \\
\hline $\begin{array}{l}\text { Transparent Procedures } \\
\text { NO } \\
\text { Yes }\end{array}$ & $\begin{array}{c}57(24.6) \\
175(75.4) \\
\end{array}$ & $\begin{array}{l}20(18.2) \\
90(81.8)\end{array}$ & $\begin{array}{l}37(30.3) \\
85(69.7)\end{array}$ & $0.032+$ \\
\hline $\begin{array}{l}\text { Appropriate number of required documents } \\
\text { No } \\
\text { Yes }\end{array}$ & $\begin{array}{c}69(29.7) \\
163(70.3) \\
\end{array}$ & $\begin{array}{l}30(27.3) \\
80(72.7)\end{array}$ & $\begin{array}{l}39(32.0) \\
83(68.2)\end{array}$ & $0.435+$ \\
\hline $\begin{array}{l}\text { Bribing to benefit from ES } \\
\text { No } \\
\text { Yes }\end{array}$ & $\begin{array}{c}221(95.3) \\
11(4.7)\end{array}$ & $\begin{array}{c}104(94.5) \\
6(5.5)\end{array}$ & $\begin{array}{c}117(95.9) \\
5(4.1)\end{array}$ & $0.627^{\dagger}$ \\
\hline $\begin{array}{l}\text { "Know someone important" to benefit from ES } \\
\text { No } \\
\text { Yes }\end{array}$ & \begin{tabular}{|c|}
$207(89.2)$ \\
$25(10.8)$ \\
\end{tabular} & $\begin{array}{c}103(93.6) \\
7(6.4) \\
\end{array}$ & $\begin{array}{c}104(85.2) \\
18(14.8) \\
\end{array}$ & $0.040+$ \\
\hline $\begin{array}{l}\text { Meeting the deadlines to benefit from ES } \\
\text { No } \\
\text { Yes }\end{array}$ & $\begin{array}{c}99(42.7) \\
133(57.3)\end{array}$ & $\begin{array}{l}42(38.2) \\
68(61.8)\end{array}$ & $\begin{array}{l}57(46.7) \\
65(53.3)\end{array}$ & $0.189+$ \\
\hline
\end{tabular}

*The absolute number and the percentage according to the columns (in brakes). ${ }^{\dagger} \mathrm{P}$ value based on the hi test square. 


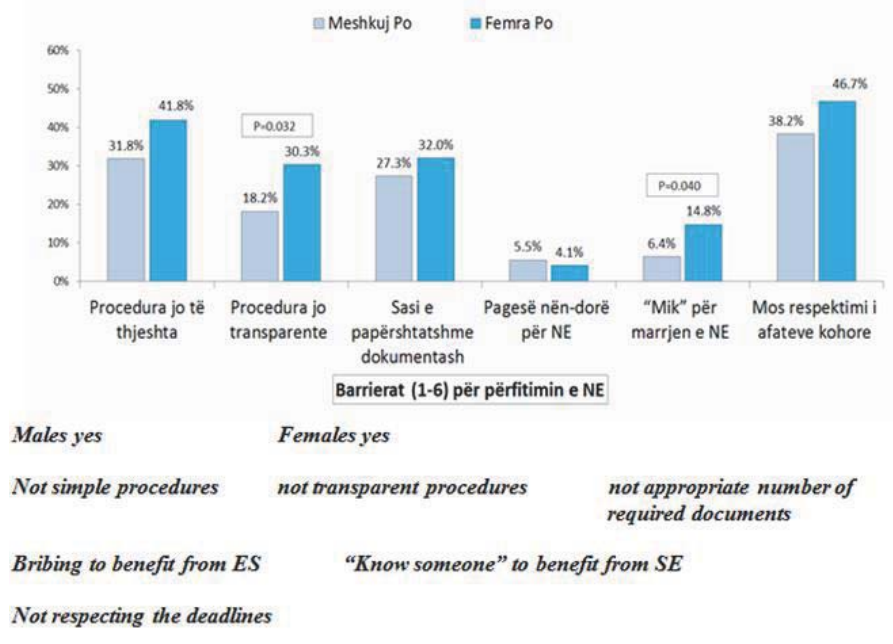

Obstacles (1-6) to benefit from ES

The graphic shows the proportion of males and females who think that the above mentioned aspects are obstacles to benefit from the economic support (ES)

The following table: Obstacles of benefiting from economic support according to the gender (continue)

\begin{tabular}{|c|c|c|c|c|}
\hline \multirow[b]{2}{*}{ Obstacles of benefiting from economic support (7-12) } & \multirow[b]{2}{*}{ Total } & \multicolumn{2}{|c|}{ Gender } & \multirow[b]{2}{*}{$P$ value } \\
\hline & & $\begin{array}{c}\text { Males } \\
(\mathrm{n}=110)\end{array}$ & $\begin{array}{c}\text { Females } \\
(\mathrm{n}=122)\end{array}$ & \\
\hline $\begin{array}{l}\text { Abusing with the benefiting procedures } \\
\text { No } \\
\text { Yes }\end{array}$ & $\begin{array}{c}159(68.5) \text { * } \\
73(31.5)\end{array}$ & $\begin{array}{l}80(72.7) \\
30(27.3)\end{array}$ & $\begin{array}{l}79(64.8) \\
43(35.2) \\
\end{array}$ & $0.192 \dagger$ \\
\hline $\begin{array}{l}\text { Illegal benefiting } \\
\text { No } \\
\text { Yes }\end{array}$ & & $\begin{array}{l}54(49.1) \\
56(50.9)\end{array}$ & $\begin{array}{l}51(41.8) \\
71(58.2)\end{array}$ & $0.265 t$ \\
\hline $\begin{array}{l}\text { Social services workers assisting in the explanation of the procedures } \\
\text { No } \\
\text { Yes }\end{array}$ & & $\begin{array}{l}20(18.2) \\
90(81.8)\end{array}$ & $\begin{array}{l}27(22.1) \\
95(77.9)\end{array}$ & $0.455^{\dagger}$ \\
\hline $\begin{array}{l}\text { The social services workers } \backslash \text { municipality are available to give the } \\
\text { information on the requirements to benefit from the ES scheme } \\
\text { No } \\
\text { Yes }\end{array}$ & $\begin{array}{l}.2) \\
6.8)\end{array}$ & $\begin{array}{l}36(32.7) \\
74(67.3)\end{array}$ & $\begin{array}{l}41(33.6) \\
81(66.4)\end{array}$ & $0.887^{\dagger}$ \\
\hline $\begin{array}{l}\text { Clear Information in Media concerning the ES scheme } \\
\text { No } \\
\text { Yes }\end{array}$ & $\begin{array}{l}113(48.7) \\
119(51.3) \\
\end{array}$ & $\begin{array}{l}52(47.3) \\
58(52.7)\end{array}$ & $\begin{array}{l}61(50.0) \\
61(50.0) \\
\end{array}$ & $0.678 \dagger$ \\
\hline $\begin{array}{l}\text { Does the political orientation affects the benefiting from the SE scheme } \\
\text { No } \\
\text { Yes }\end{array}$ & $\begin{array}{c}204(87.9) \\
28(12.1) \\
\end{array}$ & $\begin{array}{l}97(88.2) \\
13(11.8)\end{array}$ & $\begin{array}{c}107(87.7) \\
15(12.3)\end{array}$ & $0.911^{\dagger}$ \\
\hline
\end{tabular}

*The absolute number and the percentage according to the columns (in brakes). ${ }^{\dagger} \mathrm{P}$ value based on the hi test square. 
Graphic: Subject study distribution according the number of obstacles to benefit from the economic support scheme identified by them

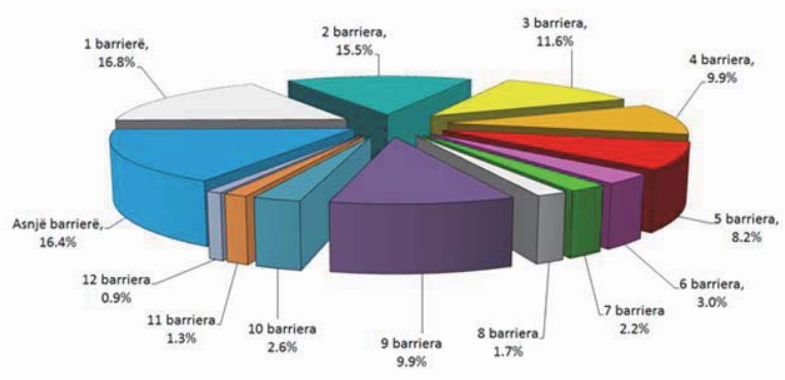

No obstacle, 1 obstacle, 2 obstacles, 3 obstacles, 4 obstacles, 5 obstacles, 6 obstacles, 7 obstacles, 8 obstacles, 9 obstacles, 10 obstacles, 11 obstacles, 12 obstacles

\subsection{Summary of the data related to the obstacles to benefit from the economic support scheme}

Concerning the obstacles to benefit from the economic support scheme, $37 \%$ of the subject thought that the procedures were not simple, $25 \%$ and $30 \%$ thought that they are not transparent or the required document number is not appropriate, $32 \%$ think that the procedures are abused with, 55\% think that there are people who benefit illegally from the economic support scheme, $5 \%$ and $11 \%$ think that you have to bribe someone or you should "know someone" to benefit from ES, $43 \%$ think that the deadlines are not respected, $12 \%$ think that political orientation effect the benefit from the ES, $20 \%$ and $33 \%$ think that the social services workers do not explain the benefiting procedure or are not willing to give the information related to the ES scheme benefiting, and 51\% think that the media information on the ES is not enough or is not clear.

The last figure is of a great interest in the context of finding the main source of information for the subject in study is the television. In general, there were not noticed statistically significant differences between the number of males and females on the obstacles listed above expect for the non transparent procedures $(30.3 \%$ of females and $18.2 \%$ of males, $\mathrm{P}=0.032)$ and the need "to know someone" to benefit from the ES scheme $(14.8 \%$ of females and $6.4 \%$ of males, $\mathrm{P}=0.040$ ).

Concerning the average number of the obstacles to benefit from the ES scheme it was $3.5 \pm 3.15$ obstacles. In $16.4 \%$ of the cases none of the listed obstacles were not reported, in $16.8 \%$ of the cases only one obstacle was reported, in $15.5 \%$ of the obstacles two obstacles, in $11.6 \%$ of the cases three obstacles and in $9.9 \%$ of the case 4 obstacles. Nevertheless, only of the study subjects (51.3\%) reported at least three obstacles whereas $30.3 \%$ reported $5-12$ obstacles in benefiting from the economic support obstacles, which is a very alarming figure.

Females reported an average higher number of obstacles in comparison with the males (3.81 vs. 3.15, respectively) but the difference it not significant $(P=0.113) A$ clear negative connection was noticed between the average number of obstacles and level of education: between persons with 0-4, 5-8 and $>8$ years of education the average number of obstacles was $6.44,2.78$ and 2.51 , respectively $(P<0.001)$. Statistically significant relation was noticed even with the health situation, the average number of obstacles would increase every time the health situation would worsen. Concerning the vulnerable persons and their families the tendency was the older their age and the bigger their number the more the obstacles they had to overcome, even though these number did not reach the statistical significance.

The questionnaire exploring the obstacles for benefiting from the economic support scheme showed a strong inner stability (Cronbach's alpfa $=0.847$ ) and the correlation coefficient split-half $=0.666$, thus evidencing a high confidence in the instrument.

In relation to the main obstacles effecting the benefiting from the economic scheme, the factorial analysis data showed that there are four main obstacles, such as:

1. Procedures simplicity;

2. Procedures transparence;

3. The documents to be submitted; and, 
4. Providing clear information by the media and the responsible institutions on the benefiting requirements.

Based on the factorial analysis, these components are responsible for approximately $66 \%$ of the variety concerning the benefiting obstacles.

The findings of this study are an asset to improve the existing economic support scheme and the new one which is being pilot implemented in Durres and some other main cities of the country. On of the news is the application online which simplifies the functional procedures, but there are still some problems concerning the calculation and the selection of the individuals and the families in need.

\section{References}

Hantrais L. Policy Review for Family and Welfare Research, for the European Commision. October 2003.

Esping-Andersen G. The Three Worlds of Welfare Capitalism. 1990.Cambridge: Polity Press

Orloff AS. Gender and the social rights of citizenship: the comparative analysis of gender relations and welfare states. American Sociological Review, 1993; 58:303-328.

O'Connor JS. Gendering welfare state regimes. Current Sociology, 1996; 44(2):1-

Kröger T. (Ed.), New kinds of families, new kinds of social care. Families, Work and Social Care in Europe. A qualitative study of care arrangements in Finland, France, Italy, Portugal and the UK.SOCCARE Project. Final report. 2004. European Commission 5th Framework Programme.

Hirschman AO. The Rhetoric of Reaction. 1991. Harvard University Press.

Lee DR. The Tradeoff between Equality and Efficiency: Short-Run Politics and Long-Run Realities. Public Choice, 1987; 53:149-65.

Crook C. The Future of the State. The Economist, 1997; S1-S48.

Howe N, Longman P. The Next New Deal. The Atlantic Monthly, 1992; April: 88-99

Alesina A, Perotti R. The Welfare State and Competitiveness. American Economic Review, 1997; 87:921-39.

Perotti R. Growth, Income Distribution, and Democracy: What the Data Say. Journal of Economic Growth, 1996; 1:149-87.

Kenworthy L. Do social-welfare policies reduce poverty? A cross-national assessment. Social Forces, 1999; 77(3):1119-1139.

Smeeding T. Poor people in rich nations: the United States in comparative perspective. Journal of Economic Perspectives, 2006; 20(1):60-90.

Clark-Kaufmann E, Duncan G, Morris P. How Welfare Policies Affect Child and Adolescent Achievement. American Economic Review, 2003; 93(2):299-303.

McKernan SM, Ratcliffe C. The effect of specific welfare policies on poverty. 2006. The Urban Institute. Washington, DC.

Whelan CT, Maitre B. Welfare regimes and social class variation in poverty and economic vulnerability in Europe: an analysis of EUSILC. Journal of European Social Policy, 2010; 20(4):316-332.

Albania history. Available: http://www.lonelyplanet.com/albania/history (consulted in July 2014).

Bertelsmann Stiftung, BTI 2014 - Albania Country Report. Gütersloh: Bertelsmann Stiftung, 2014. Available in: http://www.btiproject.org/fileadmin/Inhalte/reports/2014/pdf/BT/\%202014\%20Albania.pdf (Consulted in 30 July 2014).

UNICEF. Observer on the Children Right, Durrës District. Available in : http://www.observator.org.al/wp-content/uploads/2013/10/leaflet _durres_district.pdf (Consulted in August 2014).

Open Data Albania. Population according to the districts, the density and urbanization 2001-2013. Available in: http://open.data.al/sq/ news/lajm/lang/sq/id/716/Population-based on -districts--density-and-urbanization -2001-2013 (Consulted in August 2014). 